${ }^{1}$ Graduate Program of Orthodontics, Araras Dental School, University Center of Hermínio Ometto Foundation-FHO, Araras, São Paulo, Brazil.

${ }^{2}$ Department of Community Dentistry, Piracicaba Dental School, University of Campinas, Piracicaba, SP, Brazil.
Corresponding author:

Silvia A S Vedovello

Graduate Program of

Orthodontics-FHO

Dr. Maximiliano Baruto Av, 500 -

Jardim Universitário.

Araras, SP - Brazil.

13607-339

+55 19 3543-1423

E-mail: silviavedovello@gmail.com

Received: September 03, 2019

Accepted: April 05, 2020

\section{Influence of social capital on self-perception related to orthodontic treatment need}

\author{
Sandra D F Sedrez ${ }^{1}$, Ana Paula Terossi de Godoi ${ }^{1}$ iD , \\ Marcelo de C Meneghim² iD, Silvia A S Vedovello ${ }^{1}$ iD, \\ Giovana C Venezian ${ }^{1}$ (D), Carolina C de Menezes ${ }^{1}$ (iD)
}

Aim: To evaluate the influence of social capital on self-perception related to orthodontic treatment need. Methods: A cross-sectional study was conducted with a sample of 578 11-16 years-old adolescents from a city in southern Brazil. Social capital was evaluated using the Social Capital Questionnaire for Adolescent Students (SCQ-AS). Index of Orthodontic Treatment Need (IOTN) assessed malocclusion and self-perception related to orthodontic treatment need. Sociodemographic aspects of adolescents were also evaluated. Individual analyses were performed, relating the study variables to the outcome, estimating the odds ratio with the respective confidence intervals of $95 \%$. The variables with $p<0.20$ in the individual analyses were tested in the multiple logistic regression models, and those with $p<0.10$ remained in the model. Results: Social capital did not influence the self-perception related to orthodontic treatment need. Adolescents with high orthodontic needs were 5.35 ( $\mathrm{Cl}$ 95\%: 2.68 to 10.65) times more likely to perceived orthodontic treatment need $(p<0.05)$. Crowding and dental absence were associated with self-perception related to orthodontic treatment need $(p<0.05)$. Conclusions: Social capital did not influence the self-perception related to orthodontic treatment need.

Keywords: Index of orthodontic treatment need. Orthodontics. Self-concept. Social capital. 


\section{Introduction}

Oral health is a fundamental component of physical health and mental well-being. The values and attitudes of individuals and communities can influence oral health, as well as their experiences, perceptions, expectations and adaptability, reflecting on the physiological, social and psychological aspects that are essential for life quality?

Considering the assessment of oral health, malocclusion is a condition of high prevalence ${ }^{2}$, with direct influence on quality of life. In addition has the potential to affect biological functions, appearance, interpersonal relationships, socialization, self-esteem and psychosocial well-being ${ }^{3,4}$. On the other hand, there is no consensus if the orthodontic treatment need is perceived by adolescents ${ }^{5-7}$. Adolescents are a group exposed to situations of physical, emotional and social risks due to the environmental context ${ }^{8}$. Thus, the change from the traditional orthodontic model to a more biopsychosocial model increased interest of the literature 9 .

In the broader context of health, social capital can be defined as the interpersonal relationship networks that occur at different levels and positions of power and which have trust and reciprocity as foundations ${ }^{10,11}$. The possible influence of social capital on oral health has been highlighted from the social support ${ }^{12}$, bond and mutual understanding which contribute to the self-esteem, population well-being, quality of life and health ${ }^{11-17}$. Recent studies reported that the social capital can reduce the negative effects of social inequality, it seems to be related to the political interest of the parents of adolescents ${ }^{12}$ and it can be seen as a protective factor, in socially disadvantaged locations ${ }^{8,11,16,18}$. This concept has been used increasingly in several aspects of mental health, self-assessment in health and, especially, oral health ${ }^{8,11-17,19,20}$. Although the evidences in oral health are at an early stage of development, social capital is defined as a potential social determinant of oral health ${ }^{12}$.

Literature still lacks answers about the relationship between oral health and social capital13,14,16,17,21. According to a recent study, the association between income inequality and the oral health-related quality of life can be attenuated by contextual social capital ${ }^{21}$. On the other hand, did not affect the relationship between income inequality and oral disease, identified by professional ${ }^{21}$. In the same context of social capital, no relationship was found with dental trauma and alcohol consumption in adolescents ${ }^{17}$; however, the socioeconomic status and features of social capital may be associated with the levels of gingival bleeding among ${ }^{20}$. In addition, there was an effect of support and social cohesion on the caries index ${ }^{14}$, in adolescents and adults ${ }^{16}$, in a contextual level ${ }^{13,16}$. There is still limited and inconsistent evidence on the association between individual social capital and oral health in in the population of children and adolescents ${ }^{20}$. Likewise, it is important in the oral health context to include the study of the impact of orthodontic treatment need on social capital.

Therefore, the aim of this study was to evaluate the influence of social capital on self-perception related to orthodontic treatment need in adolescents. The hypothesis was that the perceived orthodontic treatment need has an impact on social capital. 


\section{Materials and Methods}

\section{Study design and study population}

This cross-sectional study received ethical approval from the Research Ethics Committee (\#65187817.8.0000.5385), and was carried out in south Brazil, in a city with 61,198 inhabitants, an $96.5 \%$ literacy rate and a human development index (HDI) of 0.802, between March and May 2017. All adolescents consented to participate, and their parents or guardians signed an informed consent form.

The sample size was calculated considering a 5\% significance level, test power greater than $80 \%$, and 1.7 effect size, obtaining a minimum of 495 individuals. Adolescents enrolled in public and private schools were invited to participate in the study, and only adolescents in permanent dentition were included. Exclusion criteria were current or previous orthodontic treatment and systemic diseases, such as cerebral palsy or Down syndrome. The final sample included 578 students (314 girls and 264 boys), aged 11-16-years-old.

Parents answered a sociodemographic questionnaire with information regarding family income, number of people living in the house, and level of parental education. Family income was determined based on the sum of all salaries received by active residents in the home and categorized based on the current Brazilian minimum salary; the threshold was the median response (R\$ 3.000). Mother and father's schooling were defined as the number of years of study, with eight years used as the cut-off point; the threshold was the median response.

\section{Social Capital}

The self-administered instrument used to evaluate the adolescents social capital was the Social Capital Questionnaire for Adolescent Students (SCQ-AS), developed and validated in Brazil ${ }^{22}$. This questionnaire is composed of items selected from the national and international literature and has been submitted to face validation, content analysis and analyses of internal consistency, reliability and reproducibility. The SCQ-AS questionnaire is composed of 12 items grouped into four subscales: Social Cohesion at School; Network of Friends at School; Social Cohesion in the Community/Neighborhood; and Trust at School and in the Community/Neighborhood. The answers are given in a three-point Likert scale and scores range from 12 to 36 points, with a higher score denoting greater social capital. For this study, the median was adopted to dichotomize the value in high and low social capital ${ }^{17,22}$.

\section{Self-perception related to orthodontic treatment need}

The self-perception related to orthodontic treatment need was determined by the Aesthetic Component (AC) of the Index of Orthodontic Treatment Need (IOTN) ${ }^{12}$. This index consists of a visual scale of 10 photographs of different dental arrangements, which allows adolescents to identify which photograph most closely resembles the appearance of their teeth ${ }^{23}$. The photographs from 1 to 4 are classified as no or slight need for treatment, from 5 to 7 as moderate and from 8 to 10 as severe $e^{6,7,23}$. In this study, responses from 1 to 4 were considered without orthodontic treatment need, and equal to or greater than 5, with perceived orthodontic treatment need ${ }^{24}$. 


\section{Normative orthodontic treatment need}

The Dental Health Component (DHC) of IOTN was used for a clinical assessment of orthodontic treatment need. The data were collected with the adolescents seated, under natural light, using a wooden spatula and a millimeter probe. The IOTN-DHC categorizes the unfavorable effects of different deviant occlusal traits into five grades scale of orthodontic treatment priority, and the most severe change is used for index determination. The following features are evaluated: missing teeth, overjet, crossbite, displacement of contact points (also called crowding), and overbite (including deep bite and open bite). The sample was classified as having no need for treatment when IOTN-DHC was 1 and 2, moderate need when it was 3 and high need for normative orthodontic treatment when it was 4 and $5^{6,25}$. In addition, individual aspects of malocclusion were analyzed from the IOTN-DHC components: overjet, negative overjet, overbite, open bite, crowding, posterior crossbite, dental absence and special cases. Any of the conditions mentioned are considered special cases: cleft lip; ankylosed primary tooth; dental rash prevented by crowding, incorrect dental positioning, supernumerary tooth, retained primary tooth or pathology; partially erupted; inclined or impacted tooth; and, supernumerary tooth ${ }^{23}$.

\section{Training and Calibration}

A previously trained examiner performed the exams under artificial light at the schools. Before the study began, a calibration process was conducted to obtain acceptable consistency for the malocclusion. The training stage consisted of a theoretical discussion followed by a practical stage. During training and calibration, the inter and intra-examiner agreement was estimated with the intraclass correlation coefficient (ICC) for the components of the IOTN-DHC, with an acceptable limit value greater than 0.97 .

\section{Statistical analysis}

Data analysis was adjusted in simple logistic regression models, estimating the odds ratios (OR) with their respective confidence intervals of $95 \%$. The variables with $p \leq 0.20$ in the individual analyzes, for each outcome variable, were tested in multiple logistic regression models, with the remaining variables being $p \leq 0.10$. From the models, the adjusted odds ratios were estimated with the respective confidence intervals of $95 \%$. The analyses were performed in the SAS (release 9.2, SAS Institute Inc., Cary, NC, USA). The association of clinical evaluation and self-perception related to orthodontic treatment need was performed by the Chi-square test in the Epi Info (version 7.02, Centers for Disease Control and Prevention, Atlanta, Georgia, USA).

\section{Results}

The sample consisted of 578 adolescents, 314 girls and 264 boys aged 11-16-yearsold. A total of $74 \%$ of adolescents were from families that earned up to three times the Brazilian monthly minimum wage, $47.9 \%$ of the fathers and $50.7 \%$ of the mothers had more than eight years of schooling, and $63.5 \%$ with more than four people living in the house. The adolescents presented a high social capital, with a median of 32. 
According to Table 1, adolescents with high treatment needs showed 5.35 (95\% Cl: 2.68 to 10.65$)$ times more likely to perceive the need for orthodontic treatment $(p<0.05)$. There was no significant association between sociodemographic variables, social capital and self-perception related to orthodontic treatment need $(p>0.05)$.

Table 2 showed that in $11.1 \%$ of adolescents who perceived the orthodontic treatment need, the presence of crowding or the absence of some dental element were the components associated with the treatment need perception, and crossbite obtained a score very close to significance.

\section{Discussion}

The social context can exert influence on health-related behavior ${ }^{10,17}$. However, the majority of the studies was carried out with populations of adults $14,15,18,19,21$ and little is known regarding the relationship between social capital and health outcomes among

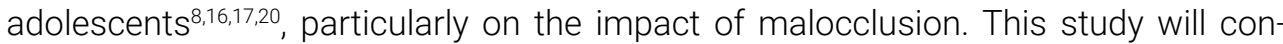
tribute to the literature with an understanding of how the capital social influence the self-perception related to orthodontic treatment need.

The study findings shows that social capital was not associated with the self-perception related to orthodontic treatment need. There is a growing application of the concept of social capital in various aspects of mental health, self-evaluation in health and, particularly, in oral health ${ }^{8,11-17,19}$. In addition, the self-perception of orthodontic treatment need (IONT-AC) is influenced by several aspects, including self-esteem ${ }^{26-29}$ This relationship may have affected the results of this study, since the average social capital was high and the need for perceived treatment was low, possibly modulated by self-esteem.

There are no reports in the literature of studies associating malocclusion and social capital. The evaluation of social capital can be performed at different levels, both individual and contextual ${ }^{10,11}$. Regardless of this assessment, there is a diversity of results when associated with other aspects of oral health. There are reports that the individual social capital was relevant in the quality of life related to the oral health of pregnant women $^{30}$ and influenced the report of toothache ${ }^{15}$. Neighborhood and family social capital also has influenced oral health reported by parents of children ${ }^{31}$ and dental losses in adults are more frequent when there is less social capital ${ }^{18}$. However, studies did not find an association between social capital and regular dental brushing, visits to the dentist, time of the last visit ${ }^{15}$ and dental trauma ${ }^{17}$. Therefore, there is no consensus about the influence of social capital on oral health and when present, whether it is on an individual or collective level. The diversity of results may be related to the sociocultural environment ${ }^{8}$, as well as the variety of tools and methodologies making it difficult to compare studies ${ }^{19}$. In this study, individual social capital evaluated characteristics such as trust ${ }^{11}$ and cohesion ${ }^{28}$ of adolescents, through the subscales of the Social Capital Questionnaire for Adolescent Students ${ }^{22}$. It is important to highlight that the population studied belongs to a city in the south of Brazil with a high human development index, compared to other cities in the country.

The present study showed that $11.11 \%$ of adolescent's perceived orthodontic treatment need (IOTN-AC); such prevalence in the literature ranges from 10 to $40 \% 5,6$. 


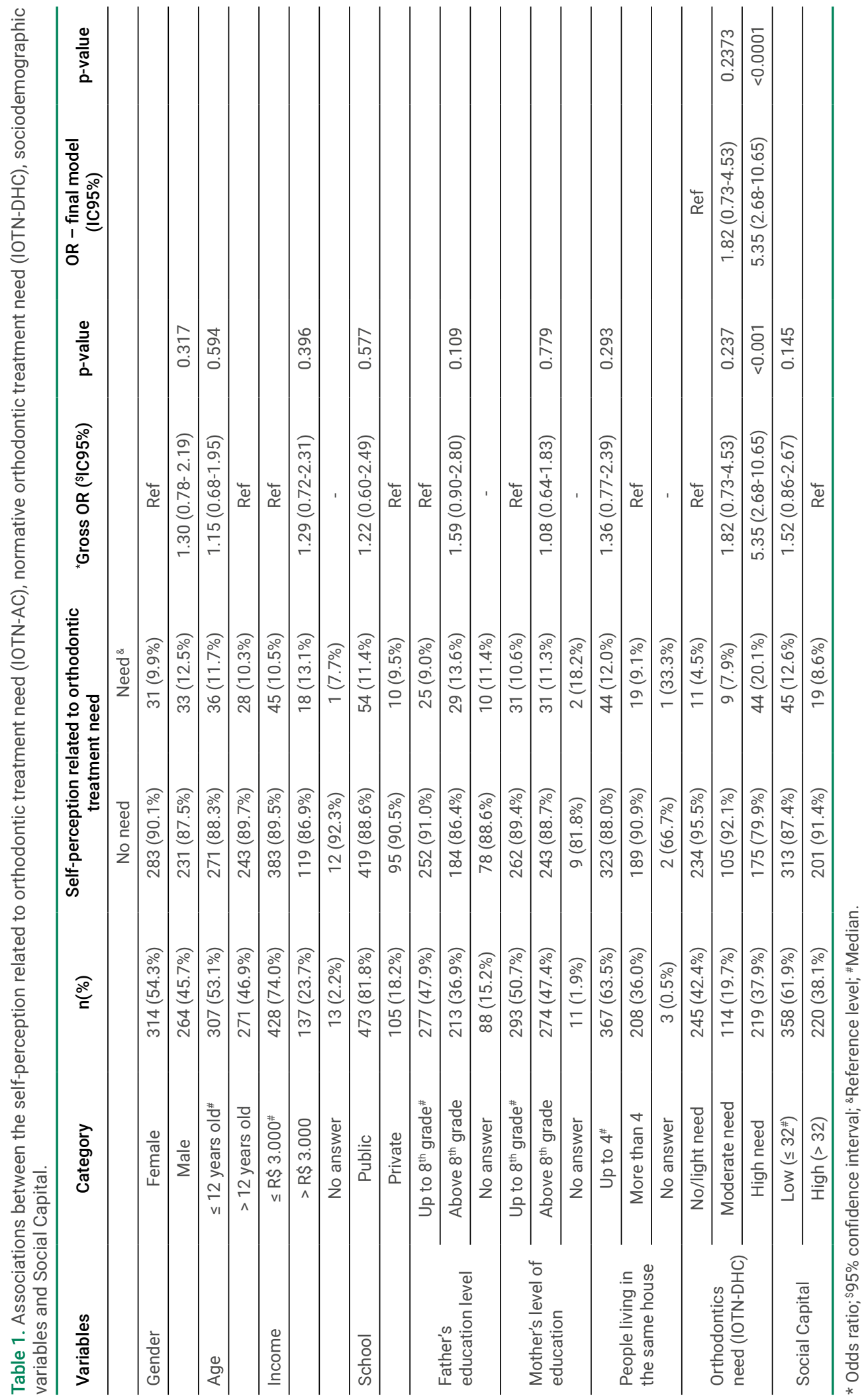


Table 2. Association of self-perception related to orthodontic treatment need (IOTN-AC) and occlusal aspects, by IOTN-DHC components.

\begin{tabular}{|c|c|c|c|c|c|c|}
\hline \multirow{3}{*}{$\begin{array}{l}\text { IOTN-DHC } \\
\text { Components }\end{array}$} & \multirow{3}{*}{ Evaluation } & \multicolumn{4}{|c|}{ Self-perception related to orthodontic treatment need } & \multirow{3}{*}{ p-value } \\
\hline & & \multicolumn{2}{|c|}{ No need } & \multicolumn{2}{|c|}{ Need $^{\#}$} & \\
\hline & & n & $\%$ & n & $\%$ & \\
\hline \multirow{2}{*}{ Overjet } & Altered & 250 & $87.1 \%$ & 37 & $12.9 \%$ & 0.210 \\
\hline & Normal & 264 & $90.7 \%$ & 27 & $9.3 \%$ & \\
\hline \multirow{2}{*}{ Negative overjet } & Altered & 26 & $81.2 \%$ & 6 & $18.8 \%$ & 0.256 \\
\hline & Normal & 488 & $89.3 \%$ & 58 & $10.7 \%$ & \\
\hline \multirow{2}{*}{ Overbite } & Altered & 258 & $88.3 \%$ & 34 & $11.7 \%$ & 0.756 \\
\hline & Normal & 256 & $89.5 \%$ & 30 & $1.04 \%$ & \\
\hline \multirow{2}{*}{ Open bite } & Altered & 48 & $87.3 \%$ & 7 & $12.7 \%$ & 0.609 \\
\hline & Normal & 472 & $89.2 \%$ & 57 & $10.7 \%$ & \\
\hline \multirow{2}{*}{ Crowding } & Altered & 280 & $86.1 \%$ & 45 & $13.9 \%$ & $0.022^{*}$ \\
\hline & Normal & 234 & $92.3 \%$ & 19 & $7.5 \%$ & \\
\hline \multirow{2}{*}{ Posterior crossbite } & Altered & 92 & $83.6 \%$ & 18 & $16.4 \%$ & 0.072 \\
\hline & Normal & 422 & $90.2 \%$ & 46 & $9.8 \%$ & \\
\hline \multirow{2}{*}{ Dental Absence } & Altered & 36 & $78.3 \%$ & 10 & $21.7 \%$ & $0.031 *$ \\
\hline & Normal & 478 & $89.8 \%$ & 54 & $10.2 \%$ & \\
\hline \multirow{2}{*}{ Special Cases ${ }^{\&}$} & Altered & 70 & $86.4 \%$ & 11 & $13.6 \%$ & 0.558 \\
\hline & Normal & 444 & $89.3 \%$ & 53 & $10.6 \%$ & \\
\hline
\end{tabular}

Chi-square; \# Median; ${ }^{*} \mathrm{p}<0.05$; ${ }^{\circledR} \mathrm{cleft}$ lip; ankylosed primary tooth; dental rash prevented by crowding, incorrect dental positioning, supernumerary tooth, retained primary tooth or pathology; partially erupted; inclined or impacted tooth; supernumerary tooth.

Higher values are expected since some studies have their samples composed by patients seeking orthodontic treatment ${ }^{5}$, suggesting a greater perception of malocclusion. Apart from that, cultural differences can influence the aesthetic perception of different societies ${ }^{32}$.

Recently, a study suggested that the greater the normative need for orthodontic treatment, the greater the need perceived by the patient ${ }^{5}$. Similar results were observed in this study, in which adolescents with a high need for normative treatment (IOTN-DHC) were more likely to need perceived treatment (IOTN-AC). Thus, although the need for perceived orthodontic treatment is low compared to normative, when it is high, it is suggested that it is more easily identified by adolescents, because the literature states that the psychosocial impact and self-perception of malocclusion increases with the increase in severity ${ }^{25}$. The presence of crowding and the absence of any dental elements were the normative components responsible for this perception; the crossbite obtained a score very close to significance suggesting that these components are more easily identified by lay people.

In this study there was no association between sociodemographic factors and need for treatment, agreeing with the previous study 6 . However, an association between normative, perceived need and age was found in the literature and the greater the age the greater the normative and perceived need ${ }^{5}$, and there are also reports that increased age and low socioeconomic status were associated with the presence of malocclusion ${ }^{4}$. 
The differentials of our study was to evaluate the influence of social capital on the orthodontic treatment need. In addition, we included the normative need, assessed clinically, with that perceived by the adolescent. As a limitation, it is worth noting the cross-sectional study design, which evaluated the impact of social capital at a given period of time. A longitudinal design is suggested in order to improve the understanding this social influence over time. Finally, considering the results, the evaluation of the influence of social capital on the perception of the orthodontic treatment need should consider different amplitudes and forms of evaluation, sociodemographic diversities, and that aspects such as self-esteem can be related in this association.

In conclusion, social capital did not influence the self-perception of the orthodontic treatment need.

\section{References}

1. Glick M, Williams DM, Kleinman DV, Vujicic M, Watt RG, Weiyant RJ. A new definition for oral health developed by the FDI World Dental Federation opens the door to a universal definition of oral health. Am J Orthod Dentofacial Orthop. 2017 Feb;151(2):229-31. doi: 10.1016/j.ajodo.2016.11.010.

2. Brazil. Health Ministry. Health Attention General Office Basic Attention Department. [SB Brazil 2003 Project: oral health conditions of brazilian population 2002-2003: main results]. Brasilia: Health Ministry; 2004. Portuguese.

3. Masood Y, Massoud M, Zainul NNB, Araby NBAA, Hussain SF, Newton T. Impact of malocclusion on oral health related quality of live in Young people. Health Qual Life Outcomes 2013 Feb;11:25. doi: 10.1186/1477-7525-11-25.

4. Vedovello SAS, Ambrosano GMB, Pereira AC, Valdrighi HC, Vedovello Filho M, Meneghim MC. Association between malocclusion and the contextual factors of quality of life and socioeconomic status. Am J Orthod Dentofacial Orthop. 2016 Jul;150(1):58-63. doi: 10.1016/j.ajodo.2015.12.022.

5. Omer YT, Bouserhai J, Hawas N, Sayed AAME. Association between normative and self-perceived orthodontic treatment need in a Lebanese population. Int Orthod. 2016 Sep;14(3):386-98. doi: 10.1016/j.ortho.2016.07.002.

6. Eslamipour F, Riahi FT, Etemadi M, Riahi A. Correlation coefficients of three self-perceived orthodontic treatment need indices. Dent Res J (Isfahan). 2017 Jan-Feb;14(1):37-42. doi: 10.4103/1735-3327.201131.

7. Santos PR, Meneghim MC, Ambrosano GMB, Vedovello Filho M, Vedovello SAS. Influence of quality of life, self-perception, and self-esteem on orthodontic treatment need. Am J Orthod Dentofacial Orthop. 2017 Jan;151(1):143-7. doi: 10.1016/j.ajodo.2016.06.028.

8. Furuta M, Ekudi D, Suzuki E, Morita M, Kawachi I. Social capital and self-rated oral health among young people. 2012 Apr;40(2):97-104. doi: 10.1111/j.1600-0528.2011.00642.x.

9. Agou S, Locker D, Strainer DL, Tompson B. Impact of self-esteem on the oral health-related quality of life of children with malocclusion. Am J Orthod Dentofacial Orthop. 2008 Oct;134(4):484-9. doi: 10.1016/j.ajodo.2006.11.021.

10. Bordieu P. The forms of capital. In: Richardson JG, editor. Handbook of theory and research for the sociology of education. New York, NY: GreenwoodPress; 1986.

11. Putnam RD. Bowling alone: the collapse and revival of American community. New York: Simon \& Schuster; 2000. 
12. Rouxel PL, Hilmann A, Aida J, Tsakos G, Watt RG. Social capital: theory, evidence, and implications for oral health. Community Dent Oral Epidemiol. 2015 Apr;43(2):97-105. doi: 10.1111/cdoe.12141.

13. Aida J, Ando Y, Oosaka M, Niimi K, Morita M. Contributions of social context inequality in dental caries: a multilevel analysis of Japanese 3-year-old children. Community Dent Oral Epidemiol. 2008 Apr;36(2):149-56. doi: 10.1111/j.1600-0528.2007.00380.x.

14. Aida J, Kuriyama S, Ohmori-Matsuda K, Hozawa A, Osaka K, Tsuji I. The association between neighborhood social capital and self-reported dentate status in elderly Japanese - The Ohsaki Cohort 2006 Study. Community Dent Oral Epidemiol. 2011 Jun;39(3):239-49. doi: 10.1111/j.1600-0528.2010.00590.x.

15. Bezerra IA, Goes PSA. [Association between social capital and oral health conditions and behavior]. Cien Saúde Colet. 2014 Jun;19(6):1943-50. doi: 10.1590/1413-81232014196.06242013. Portuguese.

16. Santiago BM, Valença AMG, Vettore MV. The relationship between neighborhood empowerment and dental caries experience: a multilevel study in adolescents and adults. Rev Bras Epidemiol. 2014;(Suppl 2):15-28. doi: 10.1590/1809-4503201400060002.

17. Paiva HN, Paiva PCP, Silva CJP, Lamounier JA, Ferreira e Ferreira E, Ferreira RC, et al. Is there an association between traumatic Dental Injury and social capital, binge drinking and socioeconomic Indicators among Schoolchildren? Plos One. 2015 Feb;10(2):e0118484. doi: 10.1371/journal.pone.0118484.

18. Borges CM, Campos ACV, Vargas AMD, Ferreira e Ferreira E. [Adult Tooth loss profile in accordance with social capital and demographic and socioeconomic characteristics]. Cien Saude Colet. 2014 Jun;19(6):1849-58. doi: 10.1590/1413-81232014196.02332013.

19. Agampodi T C, Agampodi S B, Glozier N, Siribaddana S. Measurement the social capital in relations to health in low e middle income countries (LMIC): systematic review. Soc Sci Med. 2015 Mar;128:95104. doi: 10.1016/j.socscimed.2015.01.005.

20. Tomazoni F, Vettore MV, Zanatta FB, Tuchtenhagen S, Moreira CH, Ardenghi TM. The associations of socioeconomic status and social capital with gingival bleeding among schoolchildren. J Public Health Dent. 2017 Dec;77(1):21-29. doi: 10.1111/jphd.12166.

21. Aida J, Kondo K, Kondo N, Watt R, Sheiham A, Tsakos G. Income inequality, social capital and self-rated health and dental status in older Japanese. 2011 Nov;73(10):1561-8. doi: 10.1016/j.socscimed.2011.09.005.

22. Paiva PCP, Paiva HN, de Filho PM de O, Lamounier JA, Ferreira EF, Kawachi I, Zarzar PM. Development and validation of a Social Capital Questionnaire for adolescent Students (SCQ-AS). Plos One. 2014 Aug;9(8):e103785. doi: 10.1371/journal.pone.0103785.

23. Brook P H, Shaw W C. The development of an index of orthodontic treatment priority. Eur J Orthod. 1989 Aug;11(3):309-20. doi: 10.1093/oxfordjournals.ejo.a035999.

24. Garcia G, Brandão G, Ferreira L, Meneghim MC, Pereira AC, Vazquez F, et al. [Influence of subjective determinants on the decision for orthodontic treatment in different dental caries prevalence]. RFO. 2012;17(3):303-8. doi: 10.5335/rfo.v17i3.2694. Portuguese.

25. Yi S, Zhang C, Ni C, Qian Y, Zhang J. Psychosocial impact of dental aesthetics and desire for orthodontic treatment among Chinese undergraduate students. Patient Prefer Adherence. 2016 Jun;10:1037-42. doi: 10.2147/PPA.S105260.

26. Boyce WF, Davies D, Gallupe O, Shelley D. Adolescent risk taking, neighborhood social capital, and health. J Adolesc Health. 2008 Sep;43(3):246-52. doi: 10.1016/j.jadohealth.2008.01.014.

27. Gohn MG. [Empowerment and community participation in social policies]. Saude Soc. 2004;13(2):20-31. doi: 10.1590/S0104-12902004000200003. Portuguese.

28. Elgar FJ, Trites SJ, Boyce W. [Social capital reduces socioeconomic differences in child health: evidence from the canadian health behavior in school-aged children study]. Can J Public Health. 2010 Nov-Dec;101 Suppl 3:S23-7. France. 
29. Badran SA. The effect of malocclusion and self-perceived aesthetics on the self-esteem of a sample of Jordanian adolescents. Eur J Orthod. 2010 Dec;32(6):638-44. doi: 10.1093/ejo/cjq014.

30. Lamarca GA, Leal MC, Leaos ATT, Sheihams A, Vettore MV. The difference roles of neighborhood and individual social capital an oral health-related quality of life during pregnancy and postpartum a multilevel analysis. Community Dent Oral Epidemiol. 2014 Apr;42(2):139-50. doi: 10.1111/cdoe.12062.

31. Reynolds JC, Damiano PC, Glanville JL, Oleson J, MacQuistan MR. Neighborhood and family social capital and parent-report oral health of children in lowa. Community Dent Oral Epidemiol. 2015 Dec;43(6):569-77. doi: 10.1111/cdoe.12182.

32. Heravi F, Farzanegan F, Tabatabaee M, Sadeghi M. Do malocclusions affect the oral health-related quality of life? Oral Health Prev Dent. 2011;9(3):229-33. 